Inflammation, Vol. 14, No. 5, 1990

\title{
TIME-DEPENDENT INHIBITION OF OXYGEN RADICAL INDUCED LUNG INJURY ${ }^{1}$
}

\author{
DAVID E. GANNON, ${ }^{2}$ XUANMIN HE, PETER A. WARD, \\ JAMES VARANI, and KENT J. JOHNSON \\ Department of Pathology \\ The University of Michigan Medical School \\ Ann Arbor, Michigan
}

\begin{abstract}
Experimental acute lung injury mediated by reactive metabolites of oxygen can be inhibited by the antioxidant enzymes catalase and superoxide dismutase (SOD). However, the specific time interval during which these enzymes must be present in order to cause protection is not well defined. Using two experimental models of oxidant-dependent acute lung injury, one involving the intratracheal injection of glucose, glucose oxidase, and lactoperoxidase and the other involving the intravenous injection of cobra venom factor (CVF), we investigated the effects of delaying antioxidant administration on the outcome of the inflammatory response. In both cases, the protective effects of catalase and SOD were rapidly attenuated when their administration was delayed for a short period of time. For example, intratracheal catalase resulted in $98 \%$ protection when given simultaneously with the glucose oxidase and lactoperoxidase, but only $13 \%$ protection when the catalase was delayed 4 min. Likewise, in the CVF-induced lung injury model, intravenous catalase resulted in $40 \%$ protection when given simultaneously with the CVF, but only $2 \%$ protection when the catalase was delayed $20 \mathrm{~min}$, even though the peak of the injury occurred hours after the initiation of the injury. A similar time dependence was seen with SOD. These results indicate that antioxidant therapy is required early in the course of oxygen radical-mediated acute lung injury for effective protection.
\end{abstract}

\section{INTRODUCTION}

Over the past few years, there have been a large number of studies that have illustrated the phlogistic potential of reactive oxygen radicals in the lung. In

\footnotetext{
${ }^{1}$ Supported in part by the National Institutes of Health grants HL34635 and HLA2607.

${ }^{2}$ Dr. Gannon's current address is: Department of Medicine, University of Vermont College of Medicine, Given Medical Building, Burlington, Vermont 05405-0068.
} 
humans the strongest evidence that oxidants are involved in lung injury comes from studies on patients with the adult respiratory distress syndrome (ARDS) or infant RDS. There is evidence of oxidant generation in the lungs of these patients as well as oxidative inactivation of alpha-1-PI (1-3). Other types of acute lung injury where reactive oxygen products are implicated include those caused by external agents that induce oxidant formation such as radiation (5), paraquat (5), endotoxin (6) as well as those agents that contain oxidants such as hyperoxia (7), nitrous dioxide (8), and oxidants present in cigarette smoke (9).

There is a wealth of experimental data illustrating the toxic nature of oxidants. Oxidants are capable of injuring a variety of cells in culture (10-14). Oxidants also are capable of altering extracellular matrix components (15-20), inactivating proteolytic enzymes such as trypsin, chymotrypsin, and elastin as well as the major antiprotease, alpha-1-PI (21-23) and various other biologically important mediators such as the chemotactic peptide C5a (24).

In the isolated perfused lung system and in intact animals, enzymes and enzyme substrates such as xanthine-xanthine oxidase and glucose-glucose oxidase that directly produce superoxide anion $\left(\mathrm{O}_{2}{ }^{-}\right)$and hydrogen peroxide $\left(\mathrm{H}_{2} \mathrm{O}_{2}\right)$ cause acute lung injury that can be inhibited by SOD, catalase, and hydroxyl radical scavengers or iron chelators (25-26). Stimulated neutrophils or macrophages have the same spectrum of injury. In the intact animals, acute lung injury induced by immune complexes, systemic complement activation, endotoxin, and thermal injury seem to be largely mediated by the formation of oxidants by neutrophils and macrophages $(16,27-31)$. In the majority of these systems the addition of the antioxidants and/or iron chelators at the time of the initiation of the injury is very protective, with the bulk of the evidence favoring the concept that the hydroxyl radical $(\cdot \mathrm{OH})$ is primarily responsible for the initiation of the tissue injury $(27,29)$.

In all of the in vivo studies, antioxidant inhibition of the lung injury has been accomplished by giving the inhibitors either before or during the initiation of the injury. No studies to date have looked at the time dependence of antioxidant inhibition of acute lung injury. This is an especially relevant question in view of recent studies suggesting that oxidants are not primarily responsible for vascular as well as some types of glomerular injury (32). To assess this question we looked at the effects of delaying antioxidant therapy in two experimental models of oxygen radical dependent lung injury: glucose-glucose oxidase and CVF-induced lung injury. In the studies described below we provide evidence that antioxidant inhibition of the lung injury in these models is time dependent, with the inhibitors only able to fully protect if present at the beginning of the injury even though the full intensity of the injury occurs over several hours. 


\section{MATERIALS AND METHOD}

Animals and Reagents. Pathogen-free 300-to 350-gram male Long Evans rats were used in these studies. They were obtained from Charles River (Portage, Michigan) and were housed in a sterile laminar flow facility until the time of the experiments.

Glucose oxidase (from Aspergillus niger), lactoperoxidase (from bovine milk), and glucose were all obtained from Sigma Chemical Co. (St. Louis, Missouri). The concentration of the glucose oxidase was $1200 \mathrm{units} / \mathrm{ml}$. and the lactoperoxidase $340 \mathrm{units} / \mathrm{ml}$. These stock solutions were diluted to an appropriate concentration in phosphate-buffered saline ( $\mathrm{pH} 7.4)$. In vitro kinetic analysis of $\mathrm{H}_{2} \mathrm{O}_{2}$ production by the glucose oxidase was assessed spectrophotometrically (33).

Cobra venom factor (CVF) was obtained from crude lyophilized cobr (Naja naja) venom by ion-exchange chromatography and gel filtration (30). To assess the functional activity of the CVF, rats were injected intraperitoneally with 4 units of CVF and complement activity in these animals was assessed. The CVF injection resulted in complete abolition of $\mathrm{CH}_{50}$ hemolytic activity $(<25$ $\mathrm{CH}_{50}$ units/ml serum).

Catalase and SOD were obtained from Enzon, Inc. (Piscataway, New Jersey). These enzymes were conjugated to polyethylene glycol (PEG) and are sterile preparations stored in membrane topped vials. For the in vivo experiments, the concentrations used of the PEG-SOD and PEGcatalase was 10,000 units/animal.

Animal Models of Lung Injury The rats were anesthetized using ketamine anesthesia (Warner Lambert, Morris Plains, New Jersey). In the CVF model of lung injury, the rats were injected intravenously with 10 units of CVF in $0.5 \mathrm{ml}$ of sterile saline or $0.5 \mathrm{ml}$ of saline alone. In those animals where SOD and catalase were also used, 10,000 units of either the PEG-SOD or PEGcatalase were injected intravenously with the CVF at time zero as well as 10 and $20 \mathrm{~min}$ later when the experiments were terminated at $30 \mathrm{~min}$. When the injury was assessed at $2 \mathrm{~h}$ catalase and SOD were both used with the catalase given at time zero, $30 \mathrm{~min}$ and $1 \mathrm{~h}$ later, whereas. for the SOD studies the SOD was given at time zero and $30 \mathrm{~min}$ later. In all cases the intensity of the lung injury was assessed by permeability changes and morphology as described below and the degree of lung injury compared to positive controls (no inhibitor) as well as antioxidants at time zero. The animals were sacrificed $30 \mathrm{~min}$ or $2 \mathrm{~h}$ later, depending on the study and the degree of lung injury quantitated as described below.

In those studies were lung injury was induced by glucose, glucose oxidase, and lactoperoxidase, the following methods were used. The animals under ketamine anesthesia underwent a tracheostomy and $1 \mathrm{mg}$ of glucose, 50 units of glucose oxidase and 1.7 units of lactoperoxidase were instilled the lung at the level of the carina via a fine Teflon catheter in a volume of $200 \mu$ l. Following this the catheter is removed and the incision closed with silk suture. In those experiments where catalase was used, 10,000 units of PEG-catalase was given at time zero with the other reactants or at the later time intervals as outlined in the experimental design. In order to ensure that the delayed catalase instillation was in the same site in the lungs as the enzyme substrate system, the catheter was left in place until after the catalase instillation. The animals were sacrificed after $4 \mathrm{~h}$ and the degree of lung injury assessed as described below.

Quantitation of Lung Injury. The degree of lung injury was assessed by two techniques. The first technique involves the use of ${ }^{125}$ I rat albumin as a marker of permeability changes in the lung. The radiolabeled albumin is injected intravenously at the beginning of the experiment. At the time of sacrifice, $1 \mathrm{ml}$ of blood was collected from the vena cava and the amount of radioactivity counted with a gamma counter. The heart and lung are then removed en bloc and $10 \mathrm{cc}$ of sterile saline perfused through the right ventricle of the heart to remove any radioactivity from the pul- 
monary circulation. The lungs were then counted for total radioactivity and the ratio of this value compared to the radioactivity in $1 \mathrm{cc}$ of blood is called the permeability index. This technique has: been used for many years in our laboratory and in conjuctioon with morphology, has proven to be a sensitive indicator of lung injury $(27,30,31)$.

Correlative morphology studies also were used to assess the degree of lung injury. At least two animals per group were assessed this way. At the time of sacrifice the lungs were inflated with glutaraldehyde and at least two biopsies from each lobe of the lung were assessed by $1-\mu \mathrm{m}$ "thick" sections embedded in Epon and stained with toluidine blue. From these thick sections at least five sections were selected for ultrastructural analysis. These biopsies were thin sectioned, and processed routinely for ultrastructural analysis using a Phillips 401 transmission electron microscopy.

Proteolytic Enzyme Assay. Proteolytic enzyme activity in lung lavage fluids was assessed using a modification of the procedure described by Anson (34). Briefly, lung lavage fluids were mixed with $0.5 \mathrm{ml}$ of a $5 \mathrm{mg} / \mathrm{ml}$ solution of hemoglobin in PBS, $\mathrm{pH} 7.2$, and incubated at $37^{\circ} \mathrm{C}$ for $18 \mathrm{~h}$. At the end of the incubation period, the intact protein was precipitated with tricholoracetic acid ( $10 \% \mathrm{v} / \mathrm{v}$, final concentration) and centrifuged at $2000 \mathrm{rpm}$ for $20 \mathrm{~min}$. The amount of protein fragments remaining in solution was then quantified using the Folin reagent and compared to a hemoglobin standard curve. In all experiments, hemoglobin was incubated with varying concentrations of purified chymotrypsin. The amount of proteolytic activity in the lavage fluid was then estimated based on the chymotrypsin standard curve.

\section{RESULTS}

Time Dependence of Catalase Inhibition of Glucose-Glucose Oxidase-and Lactoperoxidase-Induced Lung Injury. The intratracheal instillation of glucose and glucose oxidase results in severe hemorrhagic lung injury that peaks in intensity at 4-6 h. The addition of lactoperoxidase results in more severe injury, suggesting that hypochlorous acid $(\mathrm{HOCl})$ is involved. Previous studies have demonstrated that if antioxidants, in particular catalase, are present at the initiation of the injury (time zero), there is a marked protective effect with over $80 \%$ of the lung injury suppressed as compared to the positive controls (25). This is illustrated again in this study as shown in Figure 1, where the coinstillation of 10,000 units of PEG-catalase with the glucose, glucose oxidase, and lactoperoxidase provided virtually complete protection. For these studies we were interested primarily in determining the time dependence of the protective effect of catalase. To do this we simply delayed the catalase instillation into the lungs $0.5-4 \mathrm{~min}$ after the instillation of the enzyme substrate system, taking care to leave the catheter in place to ensure that the catalase was infused into the same location. As illustrated in Figure 1, the ability of catalase to inhibit the lung injury was found to be markedly diminished over a short period of time. Delaying the catalase infusion only $0.5 \mathrm{~min}$ diminished the protective effect of the catalase by about $20 \%$. This loss of protection by catalase was accentuated when catalase infusion was delayed further. For example, a delay of 2 min resulted in only $50 \%$ suppression from the lung injury, whereas at 4 


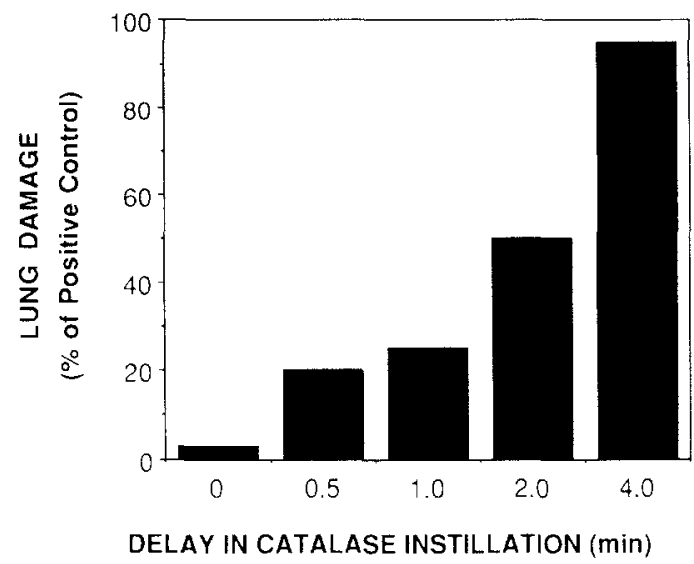

Fig. 1. The ability of catalase to inhibit glucose oxidase-induced lung injury appears restricted to its being present at the initiation of the injury. An average of four rats were used at each time point. $P<0.05$.

min the protective effects of catalase are essentially lost. This loss of an inhibitory effect of catalase after $4 \mathrm{~min}$ is especially striking in view of the fact that in vitro significant $\mathrm{H}_{2} \mathrm{O}_{2}$ production occurs for greater than 45 min after the initiation of the reaction (Figure 2) and that the peak of the acute lung injury in this model does not occur until 4-6 $\mathrm{h}$ later. Thus, in summary, catalase suppres-

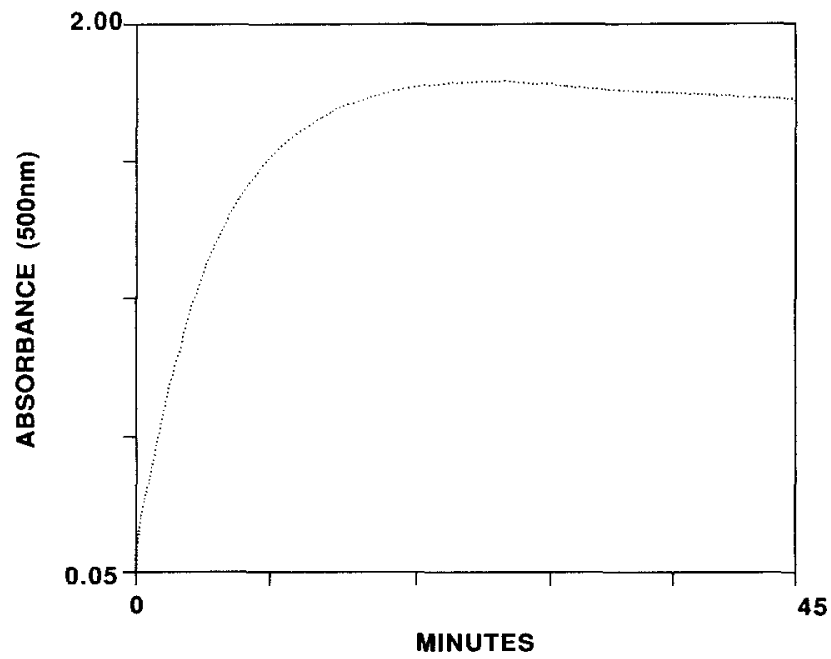

Fig. 2. In vitro kinetic production of $\mathrm{H}_{2} \mathrm{O}_{2}$ by 0.1 units of glucose oxidase illustrating a sustained production for over $45 \mathrm{~min}$. 
sion of glucose, glucose oxidase, and lactoperoxidase-induced lung injury appears to be strikingly time dependent, with catalase providing maximal protection only at the initiation of the injury.

Time Dependence of Antioxidant Inhibition of CVF-Induced Lung Injury. The intravenous injection of purified cobra venom factor (CVF) into rats results in systemic complement activation, neutrophil adherence to pulmonary capillary endothelial cells, and subsequent injury to these cells with edema, fibrin generation, and hemorrhage. The evidence that neutrophil-derived oxygen radicals are responsible for the injury in this model is based on demonstrating a marked protective effect when antioxidants or iron chelators were given at the same time or prior to the $\operatorname{CVF}(30,31)$. In this model we again wanted to determine the time dependence of SOD and catalase inhibition similar to the studies done in the glucose, glucose oxidase, and lactoperoxidase-induced injury. In initial studies, as shown in Figure 3, we assessed the effect of delaying catalase administration on the degree of lung injury present $30 \mathrm{~min}$ after the CVF injection. When 10,000 units of PEG-catalase were given simultaneously with the CVF at time 0 , there is a $45 \%$ inhibition of the lung injury as measured by permeability changes. This degree of inhibition is similar to that previously described $(30,31)$. However, if the catalase instillation is delayed for a few minutes, this protective effect is lost rapidly. Thus, if catalase treatment is delayed until $10 \mathrm{~min}$ after the CVF injection, the degree of inhibition is only $28 \%$ as compared to the CVF-positive control animals. Even more striking is the fact that after 20 min catalase has virtually no suppressive effects, with only around 5\% inhibition of the injury.

In order to determine the full extent of the time dependence of antioxidant

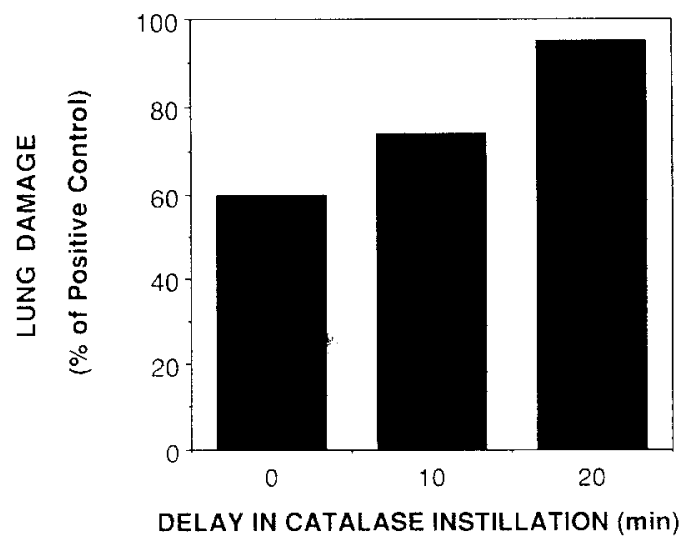

Fig. 3. The ability of catalase to inhibit CVF lung injury is most pronounced if catalase is present at the initiation of the injury. The numbers of animals tested per time point was $5-10 . P>0.05$. 
inhibition in this model, we looked at time course studies of SOD and catalase inhibition over a longer period of time $(2 \mathrm{~h})$ in order to make sure that we were not missing a delayed effect of the antioxidants. As shown in Table 1, 10,000 units of PEG-SOD when coadministered with the CVF causes a $41 \%$ inhibition of the lung injury as compared to the positive control animals. However, when SOD treatment is delayed until $30 \mathrm{~min}$ after the CVF injection there is no evidence of any inhibition. Therefore, the protective effects of SOD in this model appear clearly to be time dependent.

We also looked at the delayed effect of catalase instillation at this later 2-h time point. As also shown in Table 1, catalase given at time zero with the CVF causes a $43 \%$ inhibition of the lung injury at $2 \mathrm{~h}$. However, once again, if catalase administration is delayed, its protective effects are rapidly lost. For example, delaying the catalase administration for 30 min results in only an $8 \%$ reduction in the degree of injury, whereas a delay of 60 min results in no protection. Thus in the CVF model of lung injury, like the glucose-glucose oxidase and lactoperoxidase system, the inhibition by antioxidants clearly appears to be time dependent.

Morphology Studies. Correlative morphology studies were performed in addition to the permeability studies. The morphologic alterations seen with delaying catalase infusion in the glucose, glucose oxidase, and lactoperoxidase model of lung injury are illustrated in Figure 4. As shown in Figure 4A, the instillation of this enzyme substrate system produces significant acute lung injury at $4 \mathrm{~h}$ with neutrophils present in alveolar capillaries, injury to endothelial and epithelial cells, edema with intraalveolar hemorrhage, and fibrin generation. If catalase is given at time 0 with the reactants, there is a marked protective effect

Table 1. Time-Dependent Suppression of CVF-Induced Lung Injury by SOD and CATALASE at Two Hours

\begin{tabular}{lclcc}
\hline \multicolumn{1}{c}{ Experiment } & $N$ & Tisste injury $^{a}$ & $\begin{array}{c}\text { Protection } \\
(\%)\end{array}$ & Significance \\
\hline $\begin{array}{l}\text { SOD Inhibition } \\
\text { CVF alone (no SOD) }\end{array}$ & 4 & $0.487 \pm 0.051$ & & \\
CVF + SOD (time 0) & 5 & $0.286 \pm 0.029$ & 41 & $<.05^{b}$ \\
CVF + SOD (30 min later) & 5 & $0.556 \pm 0.24$ & 0 & $<.05^{c}$ \\
Catalase Inhibition & & & & \\
CVF alone (no catalase) & 2 & $0.635 \pm 0.16$ & & $<.05^{b}$ \\
CVF + catalase (time 0) & 4 & $0.378 \pm 0.087$ & 43 & $<.05^{c}$ \\
CVF + catalase (30 min later) & 2 & $0.59 \pm 0.014$ & 8 & $<.05^{c}$ \\
CVF + catalase (1 h later) & 3 & $0.66 \pm 0.28$ & 0 & \\
\hline
\end{tabular}

\footnotetext{
${ }^{a}$ Assessed by radiolabeled permeability markers as detailed in Materials and Methods.

${ }^{h}$ As compared to positive control animals.

${ }^{c}$ As compared to animals given antioxidants at time 0 .
} 


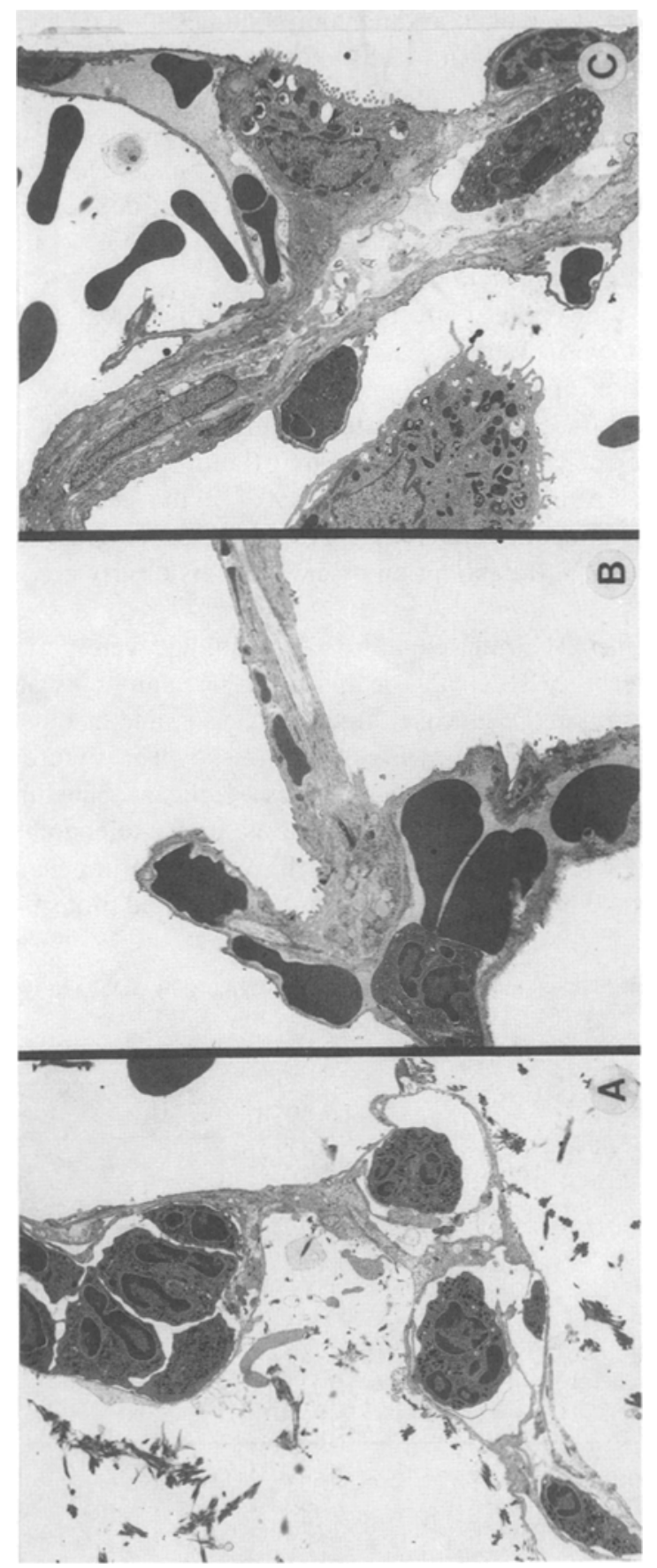

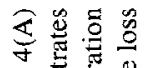

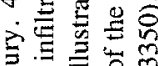

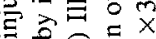

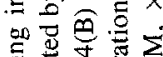
密的

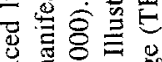
喜哭 焉 $\times$

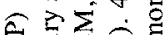

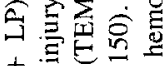
垴 $\overline{\mathrm{m}}$ 记 0. 和品

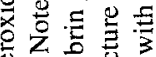
这 总密总 둥

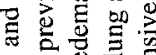
左 वृ के है है 各告 $0+\frac{0}{0}$ 80 웡 कo $\frac{3}{8}$ 家 的荅品

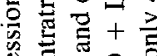
. 8 응 政 क 잉

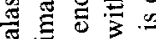
语 0 口 焉. 엉

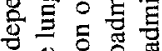
을

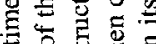

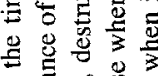
政 s

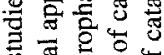
के नु 응 응 훙 石究 $\rightarrow$ 政

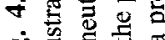

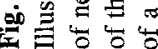


with neutrophils still present, but there is no evidence of injury (Figure 4B). By comparison, if catalase administration is delayed for 4 min (Figure 4C), much of the protective effect of catalase is lost as illustrated by edema and intraalveolar hemorrhage. Much the same histologic picture is seen in the CVF lung injury model. As shown in Figure 5A, the intravenous injection of CVF induces neutrophil emigration into the lung and endothelial cell injury with subsequent edema and intraalveolar hemorrhage. If catalase is given at time 0 with the CVF, some decrease in the intensity of the lung injury is observed, although neutrophils are still present in alveolar capillaries (Figure 5B). However, delaying the catalase treatment for 20 min causes no apparent decrease in the lung injury (Figure 5C). Thus, the morphology studies correlate well with the permeability studies in confirming the time dependence of antioxidant inhibition of the lung injury in these two models.

Protease Activity in Lung Lavage Fluids from Control and Glucose-Glucose Oxidase-Injured Rats. Lung lavage fluids were obtained from control and glucose-glucose oxidase -injured rats and assayed for proteolytic enzyme activity as described in the Materials and Methods section. There was detectable activity in the lavage fluid from injured rats. Activity was seen as early as $2 \mathrm{~h}$ after injury. The highest amount detected ( $4 \mathrm{~h}$ after injury) was equivalent to activity of $30 \mathrm{ng}$ of chymotrypsin (Table 2). Thus, measureable amounts of a second inflammatory mediator are present in the lungs after oxidant injury.

\section{DISCUSSION}

The results from this study provide evidence for the first time that antioxidant inhibition of oxygen radical-mediated lung injury is sharply time dependent and that the antioxidants must be present at the time of the initiation of the injury in order to be effective. This sharply defined time limit of inhibition by the antioxidants is quite surprising in view of the fact that the full expression of the injury requires hours. One possible explanation for this loss of inhibition by the antioxidants over time would be that insufficient concentrations of these agents were used. While potentially this could explain our results, further preliminary studies suggest that this is not the case. In the CVF lung injury model increasing the dosage of catalase to $40 \mathrm{mg}$ resulted in no additional protective effect (data not shown). Furthermore, the dosage of catalase and SOD used when given at time 0 was markedly protective, and therefore it seems unlikely that this loss of a protective effect of the antioxidants is dose related.

Another possibility is that the oxygen radicals produce molecular damage very rapidly, even though the full extent of the injury at the cellular and tissue levels evolves over a period of several minutes to hours. In support of this is the very short half-life of the $\mathrm{HO} \cdot(35,36)$, thought to be the species directly 


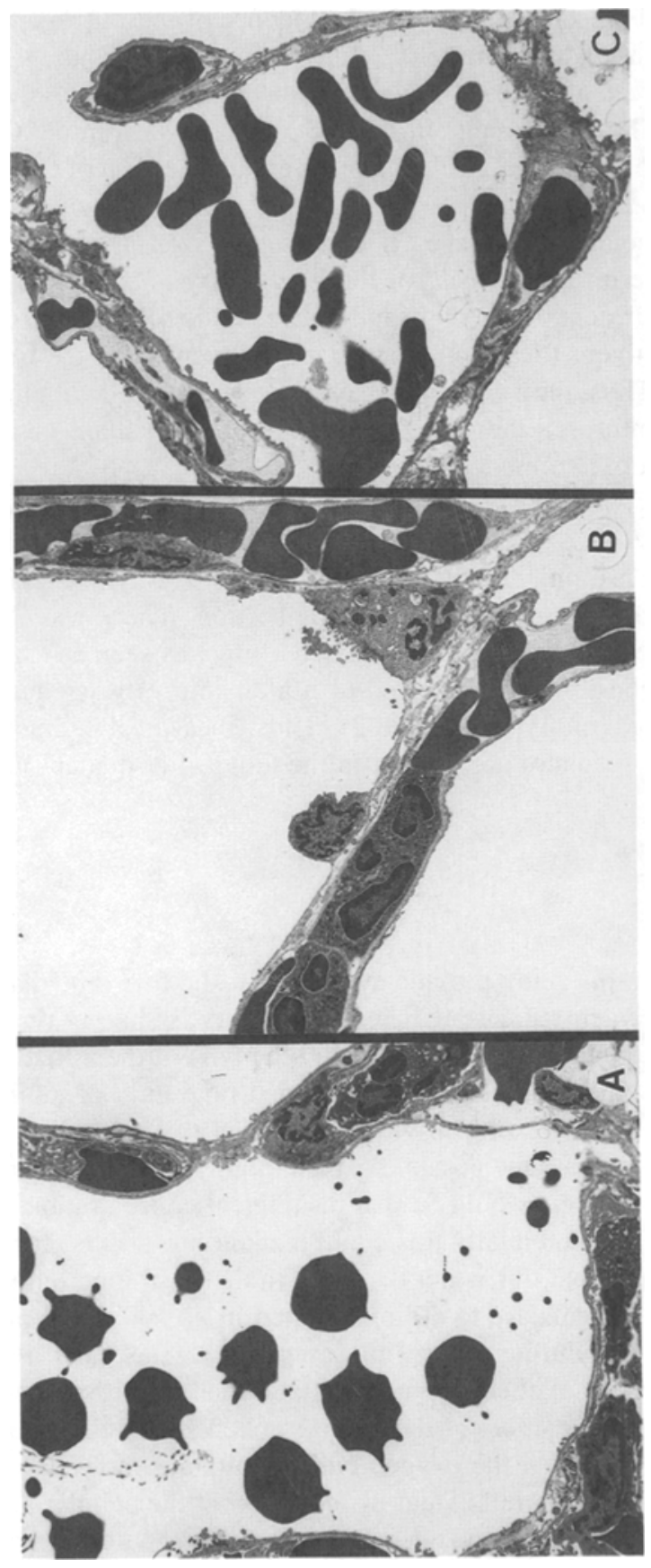

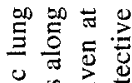

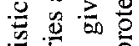
氜

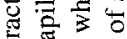
帘 要要 후 도용

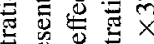
㳕吉蛋 元导界

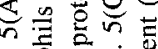

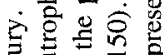
寻芯岁学出

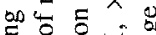

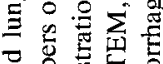
马्ष马巳 吾吉主至 跑宣言

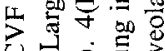

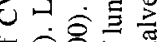
फ踪焉 吃守守

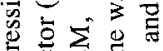

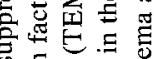
क E 0 品 兽焉焉. 要 ᄂ융류 \& 동ㅎㅇ용

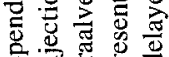

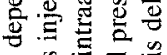

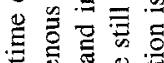

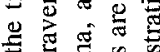

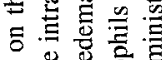

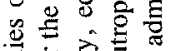

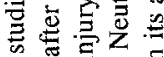

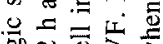
웡

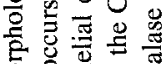

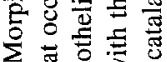

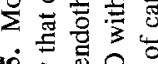
内

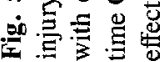


Table 2. Proteolytic Enzyme Activity in Lung Lavage Fluids from Control and Glucose-Glucose Oxidase-Injured Rats ${ }^{a}$

\begin{tabular}{lc}
\hline \multicolumn{1}{c}{ Group } & $\begin{array}{c}\text { Solubilized } \mu \mathrm{g}, \text { of Hemoglobin } \\
(X+S D)\end{array}$ \\
\hline Buffer alone & $6 \pm 3$ \\
1 ng chymotrypsin & $8 \pm 1$ \\
10 ng chymotrypsin & $43 \pm 6$ \\
100 ng chymotrypsin & $195 \pm 7$ \\
$500 \mu$ l of control lavage & $7 \pm 2$ \\
$500 \mu$ l of lavage from G-GO injured rats & $12 \pm 5$ \\
\hline
\end{tabular}

${ }^{a}$ The assay was carried out as described in the Materiais and Methods section. The values shown represent averages \pm standard deviations based on four samples in a single experiment. The experiment was repeated three times with similar results. $\mathrm{G}-\mathrm{GO}=$ glucose-glucose oxidase.

responsible for the majority of injury in these models $(27,29)$. However, in both the glucose-glucose oxidase model and the CVF model, $\mathrm{H}_{2} \mathrm{O}_{2}$ is a key intermediate. Since this reactant has a relatively long half-life (7), and in the glucose oxidase system significant $\mathrm{H}_{2} \mathrm{O}_{2}$ production occurs for greater than 45 min, it is difficult to understand why even short delays in administration of catalase would have such a profound effect on its ability to inhibit injury. Possibly, the rapid diffusion of $\mathrm{H}_{2} \mathrm{O}_{2}$ across cell membranes sequesters this reactant from inhibitors added after a short delay.

Presently available data cannot rule out this possibility. However, the data presented here is also consistent with the suggestion that while oxidants may be responsible for the initiation of tissue injury, they may not be solely responsible for the eventual severity and outcome of the inflammatory response. It may be that oxidant injury leads to tissue changes that increase the presence of other inflammatory mediators such as proteolytic enzymes. Likewise, cells injured by oxidants may become more susceptible to secondary effects of other inflammatory mediators. The demonstration of proteolytic enzyme activity in the lavage fluid of rats after experimental injury with glucose-glucose oxidase is supportive of this. Furthermore, we recently demonstrated in an in vitro model that rat pulmonary artery endothelial cells exposed to $\mathrm{H}_{2} \mathrm{O}_{2}$ became sensitive to injury by a variety of proteolytic enzymes including trypsin, chymotrypsin, elastase, and cathepsin $\mathrm{G}$, whereas control endothelial cells were much less sensitive to these proteases (37). It is of interest that in the in vitro model, the injurious effects of $\mathrm{H}_{2} \mathrm{O}_{2}$ occurred rapidly upon exposure of the cells to the oxidant. Treatment of the cells with catalase $1 \mathrm{~h}$ after exposure to $\mathrm{H}_{2} \mathrm{O}_{2}$ failed completely to prevent injury. In contrast, the proteolytic enzyme-mediated injury could be largely attenuated with appropriate inhibitors as long as $4 \mathrm{~h}$ after exposure. Thus, these in vitro observations support the concept that oxidants and 
proteolytic enzymes may act synergistically to produce the tissue injury that is characteristic of inflammation. This hypothesis is supported by studies from other laboratories where proteases are present at sites of oxidant injury in vivo $(38,39)$ and proteases and oxidants act synergistically to increase injury in the isolated perfused lung system (40). It should also be noted that other agents including cytokines (41), cationic proteins (42), and lysophosphatides (42) have also been shown in in vitro models to potentiate oxidant-induced cytotoxicity. Taken together with the data presented here, it appears reasonable to consider the interactions between various inflammatory mediators as determinants of the severity of tissue injury rather than the effects of individual mediators alone.

Acknowledgments-The authors wish to acknowledge the expert secretarial support of Ms. Kimberly Drake.

\section{REFERENCES}

1. Lee, C., A. Fein, M. Lippman, H. Holtzman, P. Kimbel, and G. Weinbaum. 1981. Elastolytic activity in pulmonary lavage fluid from patients with adult respiratory distress syndrome. N. Engl. J. Med. 304:192-196.

2. McGuire, W., R. SpragG, A. Cohen, and C. G. Cochrane. 1982. Studies on the pathogenesis of the adult repiratory distress syndrome. J. Clin. Invest. 69:543-568.

3. Merrit, T. A., C. G. Cochrane, K. Halcomb, and B. Bohl.1983. Elastase and alpha 1 proteinase activity in tracheal aspirates during respiratory distress syndrome. J. Clin. Invest. 72:656-666.

4. BRAWN, K, and I. FRIDOVICH. 1980. Superoxide radical and superoxide dismutases: threat and defense. Acta Physiol. Scand. 492 (suppl):9-18.

5. Haley, T. J. 1979. Review of the toxicology of paraquat. J. Clin. Toxicol. 14:1-46.

6. Bernard, G. R., W. D. Lucht, M. E. Neidermeyer, J. R. Snapper, M. L. Ogeltree, and K. L. Brigham. 1984. Effect of $N$-acetylcysteine on the pulmonary response to endotoxin in the awake sheep and upon in vitro granulocyte function. J. Clin. Invest. 73:1772-1784.

7. Fisher, A. B., H. J. Forman, and M. Glass. 1984. Mechanisms of pulmonary oxygen toxicity. Lung 162:255-259.

8. Fletcher, B. L., and A. L. Tappel 1973. Protective effects of dietary tocopherol in rats exposed to toxic levels of ozone and nitrogen dioxide. Environ. Res. 6:165-175.

9. JANOFF, A. 1985. Elastases and emphysema: Current assessment of the protease-antiprotease hypothesis. Am. Rev. Respir. Dis. 132:417-433.

10. Fantone, J. C., and P. A. WARD. 1979. Role of oxygen derived free radicals and metabolites in leukocyte-dependent inflammatory reactions. Am. J. Pathol. 107:397-417.

11. Nathan, C. F., L. Brukner, S. C. Silverstein, and Z. A. Cohn. 1979. Extracellular cytolysis by activated macrophages and granulocytes. I.Pharmacologic triggering of effector cells and the release of hydrogen peroxide. J. Exp. Med. 149:84-99.

12. Sachs, T., C. F. MAldaw, P. R. Craddock, J. K. BAnNer, and H. S. Jacob. 1978. Oxygen radicals mediate endothelial cell damage by complement-stimulated granulocytes. J. Clin. Invest. 61:1161-1167. 
13. Simon, R. H., C. H. Scoggin, and D. Patterson. 1981. Hydrogen peroxide causes the fatal injury to human fibroblasts exposed to oxygen radicals. J. Biol. Chem. 256:7181-7186.

14. WeISS, S. J. 1983. Oxygen as a weapon in the phagocytic armamentarium. In Handbook of Inflammation: Immunology of Inflammation, Vol. 4 P. A. Ward, editor. Elsevier Science Publishers; Amsterdam. 37-87.

15. Clark, R. A., S. Szot, M. A. William, and H. M. Kagan. 1986. Oxidation of lysine sidechains of elastin by the myeloperoxidase system and by stimulated human neutrophils. Biochem. Biophys. Res. Commun. 135:451-457.

16. Fligiel, S.E., E. C. Lee, J. P. McCoy, K. J. Johnson, and J. Varani. 1984. Protein degradation following treatment with hydrogen peroxide. Am. J. Pathol. 115:418.

17. GreEnwald, R. A. 1984. Effect of oxygen-derived free radicals on connective tissue macromolecules. In Developments in Biochemistry. W. H. Bannister, and J. V. Bannister, editors. North Holland Elsevier, Amsterdam.

18. Weiss, S. J., J. T. CuRnutTE, and S. Regiani. 1986. Neutrophil-mediated solubilization of the subendothelial matrix: Oxidative and nonoxidative mechanisms of proteolysis used by normal and chronic granulomatous disease phagocytes. J. Immunol. 126:636-641.

19. Greenwald, R. A., and W. W. Moy, 1980. Effect of oxygen-derived free radicals on hyaluronic acid. Arthritis Rheum. 23:455-461.

20. Greenwald, R. A., W. W. Moy, and D. Lazarus. 1976. Degradation of cartilage proteoglycans and collagen by superoxide radical. Arthritis Rheum. 19:799.

21. CARP, H., and A. JANOFF. 1979. In vitro suppression of serum elastase-inhibitory capacity by reactive oxygen products generated by phagocytosing polymorphonuclear leukocytes. J. Clin. Invest. 63:793-797.

22. LiN, W. S., D. A. ARMSTrong, and M. LAL. 1978. Effects of superoxide dismutase, dithiothreitol and formate ion on the inactivation of papain by hydroxyl and superoxide radicals in aerated solutions. Int. J. Radiol. Biol. 33:231-243.

23. Vartman, A. A., M. N. Weening, L. J. Homere, A. A. Meerhof, A. M. Bor, and D. Ross. 1981. Phagocytosing human neutrophils inactivate their own granular enzymes. J. Clin. Invest. 67:1541-1548.

24. Clark, R. A., S. Szot, K. Venkalasubramanion, and E. J. Schiffman. 1980. Chemotactic factor inactivation by myeloperoxidase-mediated oxidation of methionine. Immunology 124:2020-2026.

25. Johnson, K. J., J. C. FAntone, J. Kaplan, and P. A. WARD. 1981. In vivo damage of rat lungs by oxygen metabolites. J. Clin. Invest. 67:983-993.

26. Tate, R. M., K. M. Vanbenthuysen, D. M. Shasby, and I. F. McMurtry. 1982. Oxygenradical-mediated permeability edema and vasoconstriction in isolated perfused rabbit lungs. Am. Rev. Respir. Dis. 126:802-806.

27. Johnson, K. J., P. A. Ward, R. G. Kunkel, and B. S. Wilson. 1986. Mediation of IgA induced lung injury in the rat. Role of macrophages and reactive oxygen products. Lab. Invest. 54:499-506.

28. Johnson, K. J., and P. A. Ward. 1981. Role of oxygen metabolites in immune complex injury of lung. J. Immunol. 126:2365-2369.

29. Till, G. O., J. R. Hatherill, W. W. Tourtellotte, M. J. Lutz, and P. A. Ward. 1985. Lipid peroxidation and acute lung injury after thermal trauma to skin. Evidence of a role for hydroxyl radical. Am. J. Pathol. 119:376-384.

30. Till, G. O., K. J. Johnson, R. G. KunKel, and P. A. WARD. 1982. Intravascular activation of complement and acute lung injury. Dependency on neutrophils and toxic oxygen metabolites. J. Clin. Invest. 69:1126-1135.

31. WaRd, P. A., G. O. TILl, R. KunKel, and C. BeauChamp. 1983. Evidence for role of hydroxyl radical in complement and neutrophil dependent tissue injury. J. Clin. Invest. 72:789-801. 
32. Johnson, K. J., A. REHAN, and P. A. WARD. 1988. The role of oxygen radicals in kidney disease. In Oxygen Radicals and Tissue Injury. B. Halliwell, editor. FASEB; Bethesda, Maryland. 115-121.

33. Worthington, C. C. 1988. Worthington Enzyme Manual. Worthington Biochemical Corporation. Freehold; New Jersey. 155-157.

34. ANson, M. L. 1940. The estimation of pepsin, trypsin papain and cathepsin with hemoglobin. J. Gen. Physiol. 23:79-89.

35. Borg, D. C., and K. M. SchaICH. 1984. Cytoxicity from coupled redox cycling of autoxidizing xenobiotics and metals: A selective critical review and commentary on work in progress. Isr. J. Chem. 24:38-53.

36. Goldstein, S., and G. CzAPSKI. 1986. The role and mechanism of metal ions and their complexes in enhancing domage in biological systems or in protecting these systems from the toxicity of $\mathrm{O}_{2}{ }^{-}$. Free Rad. Biol. Med. 2:3-11.

37. Varani, J., I. Ginsburg, L. Schuger, D. F. Gibbs, J. Bromberg, K. J. Johnson, U. S. RYAN, and P. A. WARD. 1989. Endothelial cell killing by neutrophils: Synergistic interaction of oxygen products and proteases. Am. J. Pathol. 135:435-438.

38. Revak, S. D., C. L. Rice, I. U. Schraufstatter, W. A. Halsey, B. P. Bohl, R. M. Clancy, and C. G. COCHRANE. 1985. Experimental pulmonary inflammatory injury in the monkey. $J$. Clin. Invest. 76:1182-1192.

39. Schraufstatter, I. U., S. D. Revak, and C. G. Cochrane. 1984. Proteases and oxidants in experimental pulmonary inflammatory injury. J. Clin. Invest. 73:1175-1184.

40. Baird, B. R., J. C. Cheronics, R. A. Sanglhaus, E. M. Berger, C. W. White, and J. C. REPINE. 1986. $\mathrm{O}_{2}$ metabolites and neutrophil elastase synergistically cause edematous injury in isolated rat lungs. J. Appl. Physiol. 61:2224-2229.

41. Varani, J., M. J. Bendelow, D. E. Sealey, S. L. Kunkel, D. E. Gannon, U. S. Ryan, and P. A. WARD. 1988. Tumor necrosis factor enhances susceptibility of vascular endothelial cells to neutrophil-mediated killing. Lab. Invest. 59:292-295.

42. Ginsburg, I., D. F. Gibbs, L. Schuger, K. J. Johnson, U. S. Ryan, P. A. Ward, and J. VARANI. 1989. Vascular endothelial cell killing by combinations of membrane-active agents and hydrogen peroxide. Free Rad. Biol. Med. 7:369-376. 